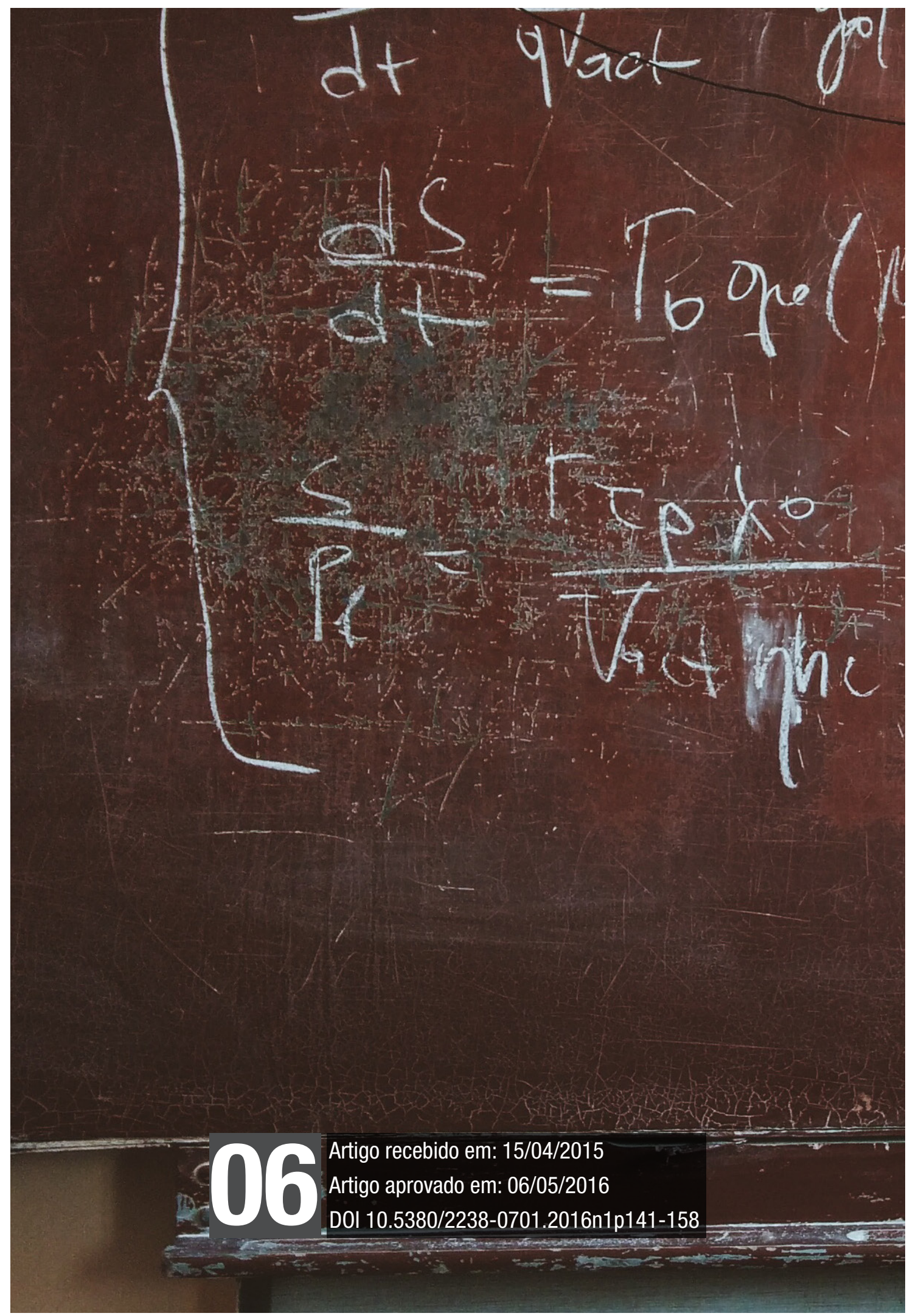


Mídia-educação. Educação para os meios.

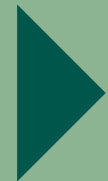




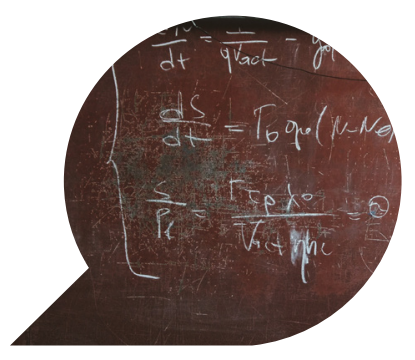

\title{
A relação mídia-educação e o desafio atual de educar para os meios
}

\author{
The media-education relationship and \\ educate the current challenge for media
}

La relación mídia-educación y el desafío
actual de educar para los medios

\begin{tabular}{c}
\hline ANDRÉ LUIS ALICE RAABE $^{*}$ \\
\hline MIRIAN R. P. RIBEIRO $^{* *}$
\end{tabular}

Resumo: Este artigo apresenta reflexões sobre os desafios e perspectivas de educar para os meios na atualidade. Trata-se mais especificamente de abrir um debate sobre a convivência dos adolescentes com as mídias digitais e sobre quem tem responsabilidades sobre a educação e orientação desta convivência. Tendo em vista a exposição exacerbada dos adolescentes à mídia, principalmente a internet e por estarem vivendo um momento de vulnerabilidade relacionado a sua pouca idade foi necessário analisar de onde vem a orientação para a convivência com as mídias digitais, levando

\footnotetext{
* Doutor em Informática na Educação (UFRGS), Mestre em Ciência da Computação (PUCRS) e graduado em Informática (PUCRS). É professor e pesquisador da UNIVALI (Universidade do Vale do Itajaí) estando vinculado ao Mestrado em Computação Aplicada e ao Mestrado e Doutorado em Educação. E-mail: raabe@univali.br

** Mestra em Educação com ênfase em Mídia Educação (UNIVALI), Pós-graduada em Marketing (PUCSC) e graduada em Comunicação Social - Publicidade e Propaganda (UPF). É professora e pesquisadora da UNIVILLE (Universidade da Região de Joinville) estando vinculada ao Curso de Publicidade e Propaganda. E-mail: mirian.ribeiro@gmail.com
} 
em consideração que essa orientação poderá partir de vários ângulos da sociedade. É esperado que este estudo contribua na discussão sobre as responsabilidades da escola e da sociedade como um espaço público da educação para as mídias digitais.

Palavras-chave: Mídia-educação; Educação para os meios; Adolescentes e mídia digital; Espaço público da educação.

Abstract: This paper reflects on the challenges and prospects of education for the media today. It is more specifically to open a debate on the coexistence of adolescents with digital media and who has responsibility for the education and guidance of this coexistence. Given the heightened exposure of adolescents to the media, especially the Internet and are living a moment of vulnerability related to his young age was necessary to analyze where does the guidance for living with digital media, taking into account that this guidance may from various angles of society. It is expected that this study will contribute in the discussion of the responsibilities of the school and society as a public space of education for digital media.

Keywords: Media education; Education for the media; Teens and digital media; Public space of education.

Resumen: Este artículo reflexiona sobre los retos y perspectivas de la educación para los medios de comunicación hoy en día. Es más específicamente a abrir un debate sobre la coexistencia de los adolescentes con los medios digitales y quién tiene la responsabilidad de la educación y la orientación de esta convivencia. Dada la mayor exposición de los adolescentes a los medios de comunicación, especialmente Internet y están viviendo un momento de vulnerabilidad relacionada con su corta edad era necesario analizar de dónde viene la guía para vivir con los medios digitales, teniendo en cuenta que esta guía puede desde varios ángulos de la sociedad. Se espera que este estudio contribuya en la discusión de las responsabilidades de la escuela y la sociedad como un espacio público de la educación para los medios de comunicación digital.

Palabras clave: Mídia-educación; La educación en medios; La educación para los medios de comunicación; Los adolescentes y los medios digitales; El espacio público de la educación. 


\section{Introdução}

Atualmente, refletir sobre a orientação e educação dos adolescentes e na sua relação de convivência com as mídias digitais remete, involuntariamente, à inter-relação entre comunicação e educação, levando em consideração o fato de que os meios de comunicação e as novas tecnologias estarem gerando novas formas de criação, circulação e recepção da informação. Nesse sentido, surgiram novos conceitos que tratam desta inter-relação: a Educomunicação; a Educação para os Meios; a Mídia-Educação.

Durante muito tempo, a força dos textos veiculados pela mídia foi ignorada pela escola. O quadro foi mudando ao longo do século XX, porque, dentre outros motivos, a atuação cada vez mais onipresente de alternativas midiáticas na vida dos estudantes fez com que grupos de professores revissem algumas questões e passassem a considerar a confluência da Comunicação com a educação (MELO; TOSTA, 2008).

No mundo atual globalizado, o objetivo dos sistemas de ensino, sejam particulares ou públicos, é o de possibilitar, prioritariamente, a todas as crianças e adolescentes de seus países uma educação básica, promovendo uma alfabetização generalizada, ou seja, que também inclua as tecnologias de informação e comunicação. Segundo Moran, Massetto e Behrens (2000, p. 67), as perspectivas do século XXI indicam a educação como o pilar para alicerçar os ideais de justiça, paz, solidariedade e liberdade.

No que se refere à área educacional, a mídia esteve sempre presente na educação formal, porém, não raras vezes, sofreu certa resistência, em relação a sua aplicação na escola. $\mathrm{O}$ impacto social causado pela penetração da tecnologia de informação e comunicação (TIC) nos últimos anos ocasionou intensas transformações nas principais instituições sociais.

Segundo Dorigoni e Silva (2008), tradicionalmente, a sociedade atribuiu a instituições escolares a responsabilidade na formação da personalidade do indivíduo tendo em vista a transmissão cultural e do conhecimento acumulado historicamente. Desde meados dos anos 1970, a educação para os meios vem se desenvolvendo em diferentes partes do mundo, sob a perspectiva de um novo campo de saber e de intervenção, com o objetivo de formar usuários ativos, criativos, críticos de todas as tecnologias de informação e comunicação. 
No entanto, Nóvoa (2008) indica que, ao longo do século XX, concepções pedagógicas, psicológicas e sociológicas da infância foram misturadas com as "ideologias da salvação", alimentando a ilusão de que a escola é um lugar de "redenção pessoal" e de "regeneração social". "Simultaneamente, a demissão das famílias e das comunidades de suas funções educativas e culturais transferia uma multidão de missões para as escolas".

Isto nos leva a refletir sobre o que Nóvoa (2008) chama de o "novo espaço público da educação", onde a educação para os meios não seria um papel somente da escola, que sofre sucessivas reformas de currículo acrescentando saberes novos, mas um espaço que existe fora da escola e que também é de aprendizado e construção do ser humano, sendo este de responsabilidade da sociedade como um todo.

A relação mídia-educação não é recente, mas está cada vez mais em evidência diante da evolução dos meios de comunicação.

\section{A relação mídia e educação}

Aponta-se de modo sucinto uma temática extremamente ampla e complexa: a integração das tecnologias de informação e comunicação aos processos educacionais. No entanto, não se pretende indicar soluções, nem delimitar um tema tão amplo, mas levantar questionamentos que nos levem a avançar para o desenvolvimento de pesquisas sobre alguns termos relacionados à formação de professores que melhor se adaptem à realidade das mídias ou ao aprofundamento de certos temas.

Muito se ouve falar da urgente integração da mídia a educação, porque o mundo continua a evoluir, e a união das duas ciências, comunicação - educação, tem muito a colaborar para o desenvolvimento do ser humano.

Antes de qualquer coisa é necessário lembrar, em primeiro lugar, de se respeitar os direitos da criança e do adolescente, especialmente no que diz respeito a uma educação de qualidade e o direito a comunicação, isso está expresso no documento de convenção da ONU de 1989 que diz:

A criança terá direito à liberdade de expressão; este direito inclui a liberdade de procurar, receber e partilhar informação de todos os tipos, independente de fronteiras, seja oral, escrita ou impres- 
sa, na forma de arte ou através de qualquer outro meio de escolha da criança (CONVENCÃO DA ONU SOBRE OS DIREITOS DA CRIANÇA E DO ADOLESCENTE, 1989).

Como defende Belloni (2005), os modos de acesso ao conhecimento de amanhã são difíceis de imaginar, e então o melhor caminho seria centrar o foco na orientação ao usuário das mídias, por duas razões: entender como funciona essa "autodidaxia" para adequar métodos e estratégias de ensino e assegurar que não se percam as finalidades maiores da educação, que é formar cidadãos competentes para vida em sociedade, o que inclui a apropriação crítica e criativa de todos os recursos técnicos à disposição da sociedade em que vivemos. Assim, como já defendia Perriault: "É urgente atualizar a tecnologia educacional porque uma nova "autodidaxia" importante está se desenvolvendo há vários anos nos jovens por meio das mídias" (1996 apud BELLONI, 2001, p.7).

A penetração das máquinas inteligentes (tablets, smartphones etc.) em nossas vidas é uma realidade irrefutável, e transformaram as relações que temos com o mundo: em meados dos anos 80 as famílias passaram a pautar suas conversas baseadas na programação da TV e até hoje de certa forma organizam nosso tempo em função de seus programas, não é diferente com a internet que hoje está em todos os cômodos da casa na mão de cada membro da família; as igrejas renderam-se aos espetáculos de grandes auditórios ditados pela mídia; as escolas na urgência de seguir as inovações criaram grandes laboratórios de informática e agora mais recentemente adquiriram tablets para que seus alunos possam acompanhar as aulas pelos livros virtuais, nada de novo, "só para modernizar mesmo", nada de modificar a metodologia de ensino, repetindo velhas pedagogias.

São imensos os desafios que estas constatações colocam no campo da educação, tanto do ponto de vista da mediação e da intervenção que exige definições e implementação de políticas públicas, da construção de conhecimento apropriado à utilização adequada dessas máquinas para fins educativos.

São inúmeros os caminhos que precisam ser repensados, onde é preciso espaço para formação ao longo da vida do educador, para ampliar o conhecimento do "professor coletivo" e multicomponente e do estudante "autônomo", onde professor e aluno deixam de ser meros receptores da mídia, mas integrando estas mídias de modo criati- 
vo, inteligente e distanciado, no sentido de desenvolver a autonomia e a competência do estudante e do educador enquanto usuários e criadores das TIC's.

Aproveitando ao máximo as potencialidades comunicacionais e pedagógicas dos recursos técnicos: criando materiais e estratégias; metodologias; formação de educadores (professores, comunicadores, produtores, tutores, etc.); produção de conhecimento.

Desde as primeiras definições em reuniões de especialistas sob o olhar da UNESCO, está presente a ideia essencial de que a educação para as mídias é a condição sine qua non da educação para cidadania.

No presente estudo buscou-se ainda uma relação, ou à similaridade entre a mídia-educação e a educomunicação, constatou-se que as duas são sinônimas no sentido de existir um reforço latente de uma educação que necessita ser repensada, reavaliada, reestudada no sentido de vislumbrar um caminho constante e aberto ligado a diferentes mídias presentes em nosso cotidiano.

Uma educação que acompanhe as diferentes mídias, e que de mãos dadas à comunicação, encontre uma forma, de a passos largos, acompanharem e orientarem os adolescentes para conviver harmoniosamente com as diferentes mídias, sem deixar de lado a essência da educação que valoriza o cidadão como um ser social que se preocupa consigo e com a sociedade.

Diante de tantas mudanças, temos os adolescentes vivendo no mundo digital, pois estão mergulhados em mundos virtuais diariamente, sem muitas vezes orientação sobre as vulnerabilidades vivenciadas nesse local.

\section{Adolescentes no mundo digital}

Refletir sobre o cenário atual no qual estão imersos, da revolução que se vive nos dias de hoje, a chamada "Revolução Tecnológica", baseada nas novas tecnologias de informação e comunicação, que modificam a base material da sociedade em ritmos acelerados, tendo como enfoque desse movimento a informação e o conhecimento, que circulam e influenciam diretamente na prática educacional. Como esses indivíduos que interferem e sofrem influências desta sociedade estão hoje aprendendo e construindo conhecimentos? Não seria interessante observar, dar voz aos adolescentes para compreender seus 
modos de interação, suas estratégias de aprendizagem? O que tanto atrai os adolescentes?

Lago (2002) questiona se os adolescentes estariam eles predispostos a desbravar esse mundo tecnológico, corajosos, sem muita noção de perigo ao "futucar" todas as novas "geringonças eletrônicas"?. No entanto, não nos restam dúvidas, pelo contrário, é isso que os encanta, o desafio de descobrir, de ultrapassar barreiras, como as fases do jogo na tela.

Essas crianças, de hoje, segundo Serres (2013), habitam o virtual. As ciências cognitivas mostram que o uso da internet, a leitura ou a escrita de mensagens com o polegar, a consulta à Wikipédia ou ao Facebook, não ativam os mesmos neurônios nem as mesmas zonas corticais que o uso do livro, do quadro-negro ou do caderno. Esses adolescentes, cada vez mais jovens, podem manipular várias informações ao mesmo tempo. Não conhecem, não integralizam, nem sintetizam da mesma forma que os adultos, seus antepassados. "Eles não tem mais a mesma cabeça".

Nessa linha, Fischer (2000 apud LAGO, 2002) afirma que os mais velhos, já não são o lugar da sabedoria, aquelas pessoas em que se busca encontrar o conselho, a voz da experiência, as chamadas "lições de vida". Dada a rapidez das mudanças tecnológicas, o site da sabedoria, paradoxalmente, pertence aos mais jovens, são eles que podem ensinar como devemos nos comunicar, como digitar um texto no computador, como acessar um endereço na Internet, como usar o controle remoto da TV ou como gravar um CD ou Blu-ray no computador.

Estas experiências e interações tecnológicas geram ações e novos costumes entre as pessoas, devido à interatividade que emerge neste contexto. Para Lago (2002), a interatividade é esse poder de interferir, de agir e perceber a reação do outro, mesmo sendo esse outro um robô, um conhecido ou desconhecido do outro lado da linha do computador, mesmo que sejam as interfaces eletrônicas como nos jogos, os "avatares" da realidade virtual.

É preciso refletir sobre a importância de participar da ação de mudança, de construção diante destas transformações. Hoje convivemos com os ciberalunos, com a cibercriança, ciberadolescente, conectados em videogames, computadores, celulares de última geração, enfim eletronicamente enraizados.

Assim como acontece com a televisão, a vontade do aluno, por 
muitas vezes, é exercer o seu poder de dono do controle remoto como se pudesse trocar de canal quando o professor inicia sua retórica, em sala de aula.

Hoje vemos nossos filhos querendo apertar "Pause" e dar um "Rew" na tela do cinema num filme de ação, onde gostariam de repetir a cena como no poder que dominam usando o DVD, o Blu-Ray, o Ipad, o Iphone, o Youtube.

É visível, e como comentou Guatarri (1990 apud LAGO, 2002), a emergência de uma mudança em "escala planetária”. Num nível micro - pais, adolescentes, escola etc. - todos atores e autores desse contexto. Mudar pode partir de dentro, e num nível macro, com as devidas definições políticas que protejam nossos bens não duráveis e permitam acesso à educação, ao social, ao econômico, ao cultural, sempre com a devida orientação.

Para Lago (2002), a velocidade de pensamento e a capacidade de filtrar informações, produzir pensamentos diante de tantos links e clicks, dar sentido a tantas imagens e discursos. Essa capacidade de administrar o caos, como algo possível de ser reconhecido e vivido, faz parte do cotidiano dos adolescentes, isso tudo se adquire instintivamente.

Os professores e os pais são os primeiros a serem atingidos por essa consciência, pois são os alunos e os filhos que estão presentes, vivendo esse movimento, mostrando que conseguem entender $o$ zapping e ouvir música e se apropriar do conhecimento, manipulando ao mesmo tempo três, quatro... janelas abertas no computador.

Vivem-se mudanças que são perceptíveis nos modos de falar e de agir de muitos alunos, de muitas pessoas, constituindo o aprendizado de outras competências demandadas por esse momento atual. E entender essas mudanças, pode levar a vivê-las mais conscientemente e naturalmente como muitos alunos, aproveitando o aprendizado com eles para dar um salto qualitativo nos processos educativos, expandindo a capacidade como educador e como autor na sociedade.

É a partir dessas questões que Lago (2002) imagina ser necessário verificar as características e contribuições destas novas tecnologias da informação e comunicação para promover uma educação mais conectada com a lógica do mundo de hoje, refletindo sobre o processo de mediação que permeia a relação pedagógica.

É necessário, ainda, que a relação e a troca de informações e conhecimento entre professores e alunos seja proporcionada pelo uso 
dessas tecnologias e aqueles se empenhem numa prática educacional democrática, onde o objetivo principal seja a construção coletiva do conhecimento.

Levando em consideração estas novas competências destes jovens, seria interessante construir uma interface entre o que os professores e pais podem contribuir no processo educativo, ressaltando que, eles também são os responsáveis pelo acesso e diálogos destes jovens com o mundo, constituindo o chamado "espaço público da educação".

\section{O novo espaço público da educação}

Para Nóvoa (2008), repensar a educação como espaço público implica em compreender as razões que impediram a escola de cumprir muitas das suas promessas históricas. É a partir daí que se pode imaginar propostas que reconciliem a escola com a sociedade e que convoquem esta última a uma maior presença na escola.

Ainda em consonância com Nóvoa (idem), "O debate não pode ser adiado", mas ao mesmo tempo reflete em como conseguir que as famílias e as comunidades sintam que a escola lhes pertence, sem que, ao mesmo tempo, elas se fechem na "sua" escola? Como conseguir que a educação responda às aspirações e aos desejos de cada um, sem ao mesmo tempo renunciar à integração de todos numa cultura compartilhada? As soluções do passado, segundo ele, não respondem mais às questões do presente.

Michel Serres (2013, p. 27), em seu livro "Polegarzinha”, discute o surgimento de uma nova era - a da revolução digital. Para Serres, nada pode ficar como antes, tudo se alterou e continuará se alterando, nomeadamente a relação pedagógica. Daí a pergunta: "Será que a revolução digital veio alterar a forma como ensinamos?" A pedagogia já modificou-se completamente com as novas tecnologias, "ainda tenta adaptar-se, mas a passos lentos".

Em suas páginas, Serres (2013) sugere um breve raciocínio. Antigamente (Anos 1960-1980), quando entrava no auditório repleto de alunos, o conteúdo da aula era relativamente desconhecido para os estudantes. Estava na era da "presunção de incompetência". Hoje em dia, qual a probabilidade e quantos alunos visitaram ou investigaram na Internet na véspera de uma aula os conceitos que o professor irá lecionar no dia seguinte? Estamos perante uma "presunção de competência". 
Atualmente, os alunos pesquisam na Internet tudo e mais alguma coisa (O saber está na Wikipédia. Muitas pessoas o fazem) e é por isso que a relação pedagógica é cada vez mais assimétrica. Já não basta ao professor lançar sobre os seus alunos uma resma de conceitos e de conhecimentos decorados, porque antes que o professor tome a palavra, o aluno já adquiriu certo número de informações. (SERRES, 2013)

Michel Serres (2013, p. 19) nos diz: "É preciso saber ouvir os estudantes", é preciso "saber o que eles sabem [...], escutar a novidade para compreender", para entender o mundo onde os alunos habitam. Uma vez percebida e assimilada a novidade, pode-se adaptar o ensino. Para poder julgar as novas tecnologias, é preciso sair do mundo anterior e entrar literalmente neste novo mundo do digital, do instantâneo, do efêmero e do virtual.

Hoje, a geração do digital tem outras relações, criou comunidades que nunca se teria imaginado antes, pois a relação estabelecida entre os saberes foi configurada de nova e profunda maneira, como salienta Serres (2013), bem como as relações pedagógica e cognitiva. Para explicar como adaptar-se a esta nova realidade, Serres (2013) propõe que se pense sobre o conceito de autoridade.

Do ponto de vista do ensino, a palavra "autoridade" torna-se imprescindível. Autoridade vem do latim "augere", que significa fazer crescer, aumentar, consequentemente, quem tem autoridade é aquele que aumenta qualquer coisa. Portanto, hoje, para ter autoridade num auditório ou numa sala de aula é preciso "aumentar" o saber (presunção de competência), fazendo funcionar o que diferencia um professor de um aluno, isto é, a "novidade, a inovação, a experiência e a inteligência”.

Elas, "as polegarzinhas" (referindo-se às adolescentes que digitam mensagens em seus celulares com os polegares), não pensam como os pais, o mundo mudou. A cultura dos antepassados (seus pais e avós) que se sustentava na visão greco-latina, no universo judaico-cristão entre outros, fica longe da deles, formatada pela mídia e a publicidade difundida pelos adultos. Os adolescentes de hoje esperam outra escola, uma que fale sua "língua", no mínimo.

Hoje os adolescentes acessam o "mundo de saberes" pelos dedos, o autor Serres (2012) propõe uma reflexão acerca das novas formas de comunicação dos adolescentes e da escola no mundo contempo- 
râneo. $\mathrm{O}$ texto, extraído de um discurso feito na Academia Francesa em 2011, inicia com a frase: "Antes de ensinar o que quer que seja a alguém, é preciso, no mínimo, conhecer esse alguém”. Esta, talvez seja a grande verdade da educação, é uma máxima que todos educadores conhecem, mas muitas vezes deixam de lado, segundo ele.

Na comunicação não é diferente, pois antes de lançar um produto no mercado, numa campanha publicitária, é preciso conhecer muito bem o comportamento e o público-alvo, nesse sentido, retoma-se a relação mídia-educação, onde a comunicação tem muito a contribuir com a educação.

Continua-se a exercer modelos de educação para os jovens, que pressupõe uma relação de emissão e recepção do conhecimento, ignorando o fato de que estes jovens produzem conhecimento o tempo todo, independentemente da influência de quaisquer adultos. Serres (2008, p.15) afirma ainda que os jovens de hoje "não têm mais o mesmo corpo nem o mesmo comportamento, e adulto nenhum soube inspirar-lhes uma moral adequada”. Com isto traz a discussão de que, talvez, esteja-se em busca de incutir no jovem valores morais com os quais os adultos já não compactuam mais, mas que são socialmente impostos.

Serres se aproxima do que se vivencia atualmente e alerta para o quanto a educação está se distanciando do mundo dos jovens. Mundo real este, que é também virtual, porque o jovem tomou o espaço virtual como público e, para Serres, as duas dimensões se entrelaçam o tempo todo. As relações que já não se faziam possíveis no real, migraram para o espaço conectado, e cresceram em volume de forma avassaladora, sendo prova disso a força de atração do Facebook, quase equivalente à população mundial. Com estas interações este adolescente adquiriu, também, novas habilidades cognitivas, que seus professores nem sempre acompanham. (2008, apud GAIDARGI, 2013)

Já Whitty (2001 apud NÓVOA, 2008, p.225) sugere algumas pistas para a renovação da educação como espaço público. Existe um campo aberto de possibilidades, entre as visões extremas do "estado" e do "mercado". "O verdadeiro desafio consiste em evitar os processos de decisão, consolidando uma responsabilidade coletiva em relação à educação, mas sem criar de novo lógicas de planificação centralizada [...] que ajudaram a legitimar a tendência atual, visando considerar a educação como bem privado e não como responsabilidade pública”.

Hoje, segundo Castells (apud NÓVOA, 2008, p.226), é preciso 
recuperar o lugar das dinâmicas associativas, desenvolvidas no seio de um conceito público de educação, permitindo evitar as tendências burocráticas e corporativistas, sem cair numa visão fragmentada dos alunos como "clientes" e das escolas como "serviço privado".

Outra sugestão de Nóvoa (2008) é pensar a escola como "realidade multipolar", reorganizada, composta de lugares físicos e de lugares virtuais, o que leva à questão da autonomia. Os sistemas de ensino, historicamente, se organizaram a partir "de cima" e adotaram estruturas burocráticas, corporativas e disciplinares, que impediram as práticas locais, familiares e tradicionais de promover a educação. A escola substituiu esses processos "informais", assumindo o monopólio do ensino. Mas este estilo de ensinar, antigo, não tem mais espaço hoje. As escolas deverão segundo ele, definir como um espaço público, democrático, de participação, funcionando em ligação com as redes de comunicação e de cultura, de arte e de ciência.

No PNE (2014-2024) já está previsto em várias metas, a participação da família como parte do sistema de ensino, onde a mesma tem papel definido no acompanhamento da vida escolar, devendo opinar em várias circunstâncias, como por exemplo, na Meta 2 item 2.9. "Incentivar a participação dos pais ou responsáveis no acompanhamento das atividades escolares dos filhos por meio do estreitamento das relações entre as escolas e as famílias".

Talvez a tecnologia venha contribuir para o fortalecimento da relação família-escola, pois a preocupação com os meios digitais, já está levando os pais a buscarem nas escolas alternativas para entender este movimento. Como acontece na rede privada de ensino, por exemplo.

Pais preocupados começaram a nos procurar buscando ajuda e orientação com relação a problemas como, por exemplo, o uso ininterrupto de celulares nas redes sociais, a perda das horas de sono para conversar virtualmente ou jogar online; a exposição e compartilhamento de fotos que colocam em risco tanto a privacidade como a segurança das famílias através das redes sociais (EDUCACAO DIGITAL, 2015, p. 3).

Tendo em vista que a revolução tecnológica tem um enorme potencial para impulsionar a aprendizagem e o conhecimento, o Colégio Salesiano de Itajaí, por exemplo, aproveita o momento para educar. Acreditam que a circunstância exige que todos os envolvidos 
sejam educados e preparados para a melhor utilização desses recursos (EDUCAÇÃO DIGITAL, 2015, p. 3).

Sabendo que educação acontece em parceria entre escola e a família, o ensino do Colégio Salesiano, acredita ser fundamental unir forças, com os principais interessados: os pais, que fariam o papel de multiplicadores para outros pais. E assim, criou-se um projeto na escola, chamado Educação digital, onde os pais voluntariamente se envolvem nas questões ligadas ao meio digital e a troca de experiências com os professores enriquecem o aprendizado fazendo surgir outros projetos lançados em sala de aula com os alunos, como cyberbulling, sexting, limites, respeito ao outro e a diversidade (EDUCAÇÃO DIGITAL, 2015, p.3).

No entanto, Nóvoa (2008) ainda sugere cautela, pois os movimentos sociais se estabelecem num voluntarismo de curta duração, ao passo que o trabalho escolar se define num tempo necessariamente longo. É por isso que é preciso reforçar as estruturas sociais ou associativas de apoio à educação. Delas, depende, em grande parte, a renovação do espaço público da educação.

O autor ainda destaca "um novo espaço do conhecimento", que os debates sobre a escola simplesmente ignoram o "saber", hoje ele está presente em vários lugares e de várias formas. Mas o momento do ensino é fundamental, segundo o autor, para revelar sua evolução histórica e preparar a sua apreensão crítica.

Nóvoa (2008) sugere quatro pontos que merecem atenção: evitar que a educação exclua a contemporaneidade, reduzindo-se apenas às formas clássicas de saber; combater as tendências de desvalorização do saber; admitir novas formas de relação com o trabalho; a realidade atual do mundo, da ciência e da arte se definem por uma complexidade e imprevisibilidade que a escola não pode ignorar mais (NÓVOA, 2008).

Enfim, Nóvoa (2008) finaliza afirmando que é necessário compreender o impacto das tecnologias da informação e da comunicação, que transportam novas maneiras de conhecer e de aprender.

Pensar os jovens de hoje, como defende Serres (2008), implica em compreender esse uso dos polegares, que mobilizam outros neurônios, pensar nas formas de se comunicar dos jovens que desenvolveram habilidades cognitivas novas, mas nunca viram um bezerro, um porco, uma ninhada.... Esses jovens não têm o mesmo contato que se tinha com o ambiente, mas lida com perfeição com as redes, com o difuso da oralidade, na busca da informação. Para eles, adoles- 
centes, o ensino proposto não faz sentido, nem a pedagogia da Grécia antiga, nem mesmo a de Gutenberg. Eles trazem à escola o novo, o que demanda uma nova pedagogia, a pedagogia da virtualidade (2008 apud GAIDARGI, 2013).

\section{Considerações finais}

As tentativas de inovação metodológica têm se chocado com a resistência dos professores que, apesar do discurso inovador ou construtivista, não transformaram em quase nada sua prática pedagógica efetiva e continuam a ser formados para repetirem velhas pedagogias, quase sempre sem novas tecnologias.

$\mathrm{O}$ que mudou de ontem para hoje? Quando nos perguntamos sobre a relação dos jovens com as mídias nos deparamos com as mudanças que ocorrem quase que diariamente com relação a estes meios.

Nos anos 1990, as crianças dos países em desenvolvimento, como o Brasil, estavam expostas mais tempo diante da TV do que a própria escola. Hoje isso também ocorre, mas com relação à internet.

Em abril de 2012, o Brasil registrou 48,9 milhões de internautas ativos (IBOPE, 2012), que acessaram a rede pelo menos uma vez no mês. Destes internautas $10 \%$ estavam na faixa etária de 12 a 17 anos. Na avaliação do analista do Ibope Nielsen Online, José Calazans, o aumento da presença das crianças na internet brasileira tem acontecido naturalmente. "Isso reflete o aumento da presença da internet em residências com crianças e os pais dando mais liberdade para que seus filhos naveguem, além do próprio interesse das crianças pela internet", explica.

$\mathrm{Na}$ década de 1990, as formas e conteúdo das mensagens às quais os jovens tinham acesso não correspondiam, na maioria dos casos, aos objetivos educativos e pedagógicos da escola, mas à lógica da economia mundial.

Naquela época, segundo Belloni (2005), as crianças e os jovens de um modo geral não estavam preparadas para resistir aos apelos persuasivos da televisão: eles faziam o consumo passivo e não tinham meios de exercer um olhar atento fazendo uma leitura crítica de suas mensagens.

Atualmente os jovens utilizam a web 2.0 onde conseguem interagir e compartilhar conhecimento, mas de onde está vindo a preparação destes jovens para o uso consciente destas novas tecnologias? A escola poderia estar presente nesta realidade. 
$\mathrm{Na}$ atual Web 2.0, não somente se consome, mas, principalmente, se produz conteúdo (VALENTE; MATTAR, 2007), o que torna a web fascinante aos jovens, pois os liberta para outro mundo onde sua condição de receptor passa a ser também de autor de sua própria história.

A escola deveria saber lidar com esses novos modos de ver, sentir e compreender, porém ela não conseguiu acompanhar o acelerado desenvolvimento tecnológico e a crescente influência dos meios de comunicação, o que gerou um descompasso entre ambos.

Diante desse impasse, educação e comunicação deveriam trabalhar juntas para tornar o processo de aprendizagem mais eficiente e integrado.

É possível, ainda, que na sociedade, fora do espaço escolar, não exista ainda a visão de que a convivência dos jovens com as tecnologias digitais crie uma nova demanda educativa e que seria dela - da sociedade - a responsabilidade sobre esta demanda.

A escola, no dizer de Nóvoa (2008), já está sobrecarregada por diversas demandas outras impostas pela sociedade. Além de ajudar os jovens a aprender e a socializar-se a escola tem recebido demandas sobre empreendedorismo, meio ambiente, saúde, relações de gênero etc. Teríamos agora uma nova exigência: a educação para os meios digitais? De quem mais pode ser esta responsabilidade? Está aberto o debate.

\section{REFERÊNCIAS}

BELLONI, Maria Luiza. O que é Mídia-Educação. 2.ed. Campinas, SP: Autores Associados; 2005.

GAIDARGI, Alessandra. Pedagogia da Virtualidade. Disponível em: $<$ http://pedagogiadavirtualidade.wordpress.com/2013/05/15/polegarzinha -uma-nova-forma-de-viver-em-harmonia-de-pensar-as-instituicoes-de-ser -e-de-saber/>. Acesso em: 21 Fev.2014.

GUATARRI, Félix. As três ecologias. Campinas, SP: Papirus, 1990.

LAGO, Andreia F. Sala de Aula: adolescentes e mídias digitais. (2002). In: ALVES, L.R.G., NOVOA, C.C.. (Org.) Educação e Tecnologia: trilhando caminhos. Salvador, BA: UNEB, 2003. Disponível em: <http://softwarelivre- 
naeducacao.wordpress.com/2009/10/20/leitura-online-educacao-e-tecnologia-trilhando-caminhos>. Acesso em: 02 Out., 2012.

MELO, José Marques; TOSTA, Sandra Pereira. Mídia \& Educação. Belo Horizonte: Autêntica Editora, 2008.

NÓVOA, A. Os professores e o novo espaço público da educação. In: Tardif, M. and Lessard, C. O ofício de professor: história, perspectivas e desafios internacionais. Petrópolis, RJ. Vozes, 2008.

PNE. Plano Nacional de Educação 2014-2024 [recurso eletrônico]: Lei no 13.005, de 25 de junho de 2014, que aprova o Plano Nacional de Educação (PNE) e dá outras providências. - Brasília: Câmara dos Deputados, Edições Câmara, 2014.

REVISTA EDUCAÇÃO DIGITAL. Projeto Educação digital. Itajaí: Colégio Salesiano Itajaí, 2015- Anual. Ano 1, número 1. Dezembro, 2015.

SERRES, Michel. Polegarzinha. Uma nova forma de viver em harmonia, de pensar as instituições, de ser e de saber; Trad. BASTOS, Jorge. Rio de Janeiro: Bertrand Brasil, 2013.

UNESCO. Padrões de competência em TIC para professores - diretrizes de implementação. Organização das Nações Unidas para a Educação, a Ciência e a Cultura. UNESCO. 2009. Disponível em: <http://unesdoc.unesco. org/images/0015/001562/156209por.pdf>. Acesso em: janeiro, 2013.

VALENTE, C.; MATTAR, J. Second Life e Web 2.0 na educação: o potencial revolucionário das novas tecnologias. São Paulo: Novatec Editora, 2007. 